\title{
Indicators of genomic evaluation of heifers using European criteria
}

\author{
Inna Uskova ${ }^{1}$, Baluash Traisov $^{2}$, Murat Baimishev $^{1}$, Khamidulla Baimishev $^{1, *}$, and Alexey Vasilev $^{3}$ \\ ${ }^{1}$ Samara State Agrarian University, 446442 Kinel, Samara region, Russia \\ ${ }^{2}$ West Kazakhstan Agrarian-Technical University named after Zhangir khan, 090009 Uralsk, Republic of Kazakhstan \\ ${ }^{3}$ Saratov State Vavilov Agrarian University, 410012 Saratov, Russia
}

\begin{abstract}
The aim of the study is improvement of productive and reproductive indices of Holstein animals used in the Russian Federation due to their genomic evaluation using European criteria for this breed. The material for the research was repair heifers in the amount of 20 heads belonging to JSC "Niva" of the Stavropol region of Samara region. The genomic estimation of heifers was carried out in France in order to reveal the degree of the forecast' reliability of productive, reproductive qualities of heifers. The material for genomic evaluation was taken from the animal's auricle by puncture. The genomic evaluation revealed that not all heifers correspond to the expected characteristics of their parents' phenotypic features. The fat and protein content of the milk was positive for all heifers, while the milk content of 7 heifers was negatively correlated. According to the results of genomic evaluation, 3 heifers are classified as excellent, 3 as moderate and 4 as weak heifers. The conducted researches on genomic evaluation of heifers in "Niva" JSC indicate the prospects of its use in selection and breeding work, as further accelerated increase in the efficiency of dairy cattle breeding without the use of progressive methods of evaluation of repair young animals will not allow to increase the productive, native and qualitative parameters of dairy productivity of cows in a short period of time. At present 17 out of 20 genome-appraised heifers have confirmed the results of the conducted researches.
\end{abstract}

\section{Introduction}

At the beginning of the 21 st century there was a true evolution of the consequences of animal breeding, which, according to scientists, can have fantastic results, which was preceded by the decoding of the human genome.

Genome - a set of hereditary material encoded in the cell of any living being. Nature used only 4 nucleotides in the process of formation of hereditary information, and scientists wrote down the genetic code according to the first letters of the names of these nucleotides. Only four Latin letters ACJT, but their variations are truly infinite. In the genetic code even invisible to the eye bacteria 2500 letters for example, but how many letters in the novel by L. Tolstoy "War and Peace".

What gives breeders knowledge of cow and bull genomes? Until now, the basis of dairy cattle breeding in our country, as before, is based on the accounting of phenotypic parameters of the controlled animals - data of the exterior, the value of milk yield, the percentage of fat, protein in milk, etc. Comparing these characteristics with the standard indicator of female peers, we estimate the possible genetic potential of the breeding stock, then the test of breeders' research is conducted from phenotype to genotype. Genome evaluation allows this process to be reversed from genotype to phenotype, which allows breeders to effectively change the phenotype of the animal, improve its characteristics, increase the productivity of cattle, which is the purpose of breeding [1, 4, 6, 17].

In 1909, the cow's genome was read. The size of the cow's genome is comparable to that of the human genome. Within one type of genome sequence each of its representatives has identical 99.9 or $0.1 \%$ - the socalled genome polymorphisms - cause differences between individuals. Obtaining full sequencing of the genome makes it possible to determine its location with a high probability of variation and to construct DNA micro-matrixes for animal genotyping $[7,10,15]$.

Genotyping is a method of complete genomic analysis - it is easier and cheaper to sequence the genome. Its essence is that not the entire genome sequence is considered, but only evenly distributed over the genome point, where the probability of replacement of letters relative to the reference genome is high. After determining the genome peculiarities, we conduct associative research - we look for the interrelation between the genome peculiarities and significant features $[14,16]$.

To obtain information about the animal's genome, a blood, wool, tissue or seed sample is taken from which the DNA molecule is extracted. It is then placed on a microcircuit that analyzes the differences between the above mentioned sequences in one nucleotide evenly distributed over the chromosomes of the animals.

\footnotetext{
$\bar{*}$ Corresponding author: baimischev_hb $@$ mail.ru
} 
Despite the mysterious name, genomic evaluation for breeding purposes is quite simple. We were aware of the genetic potential of young animals in the past by their parents' average indices, and these indices were just an average of the predicted animal productivity, for which we had to wait several years for the cow to show herself and the bull's daughter to be evaluated by the level of lactation. [2, 5].

Of particular interest is the creation of inexpensive systems for analyzing the genome of animals in the conditions of tribal households. However, these works are mainly carried out abroad: the USA, France, where for a long time now they have been using the genomic method of heifer evaluation at their enterprises. if the genomic evaluation of DNA analysis showed low milk productivity, these heifers are culled or inseminated with the seeds of bulls of meat breeds.

Many experts believe that genomic evaluation of heifers will allow them to easily and quickly solve the following issues: what heifers to keep for reproduction, what heifers can be sold as breeding heifers, what heifers to fix for what bulls, to increase the volume and quality of milk, as well as to use the results of genomic evaluation of heifers when buying them $[9,11,12]$.

L. Hansen [13] believes that the reliability of genetic evaluation of bulls of Holstein breed in terms of profitability is $38.0 \%$ for ancestors, $70.0 \%$ for genomic test $-70.0,85.0 \%$ for daughters of the first generation and fully evaluated $-99.0 \%$, which means that the result of genomic test practically doubles the genetic characteristics of the bull who does not have any daughter yet. However, this is not the final conclusion. Genomic testing improves the index (accuracy) compared to the average indexes by ancestors, but does not reflect the magnitude of changes contrary to the expectations of the expert.

Many researchers recommend that dairy producers carry out a genomic assessment of all heifers in the herd to determine in advance which one can be sold and which one can be covered with a meat bull. This routine job is very difficult to do. It is necessary to take into account all the pros and cons, which include in the conditions of especially commodity farms: environmental conditions, diseases of chicks, lack of their development, structural changes and others $[3,8,18]$.

From a brief review of the literature on animal genome assessment, it follows that in the Samara region, as in the Russian Federation, this issue should be given more attention. In this connection, we considered it possible to present the data of genomic assessment of heifers belonging to CJSC "Niva" in the amount of 20 heifers and to determine the percentage of probability of prediction of their economic and biological properties, thus, the experience of large dairy farms of the European community shows an increasing gap between the parameters of the level of milk productivity, quality indicators of milk and the fertile ability of animals.

The aim of the work is to improve the productive and reproductive indices of Holstein animals used in the Russian Federation due to their genomic evaluation using European criteria for this breed. In this connection, the following task was set:
- to determine the genetic potential of the repair young stock of JSC "Niva" in the Stavropol region of the Samara region to determine the degree of reliability of the forecasting of productive, reproductive qualities of heifers in France.

\section{Materials and methods}

The material for the research was repair heifers in the number of 20 heads in 2015-2016 year of birth belonging to JSC "Niva" Stavropol district of Samara region and their genomic evaluation in France was carried out in order to determine the degree of reliability of the forecast of productive, reproductive qualities of heifers. The material for genomic assessment was taken from the animal's auricle by puncture (Fig. 1). The biomaterial was then placed in a special container with a number and barcode.
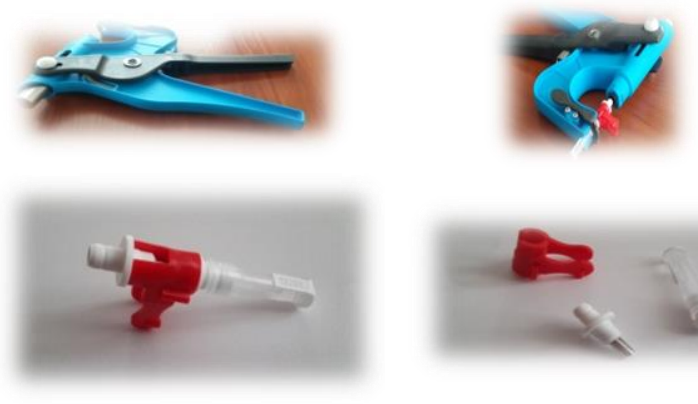

Fig. 1. Tools for taking biological material for genomic evaluation

Genomic evaluation of heifers was carried out in the laboratory of animal husbandry in Paris with the use of presented biomaterials and the database of the European criteria for the evaluation of Holstein cattle breed with the definition of the threshold of reliability of prediction on dairy productivity, fat content, protein content in milk, reproductive capacity, exterior data, udder index, calving ease, leg index, limb index, height in the withers.

According to the results of genomic evaluation, the animals were divided into three groups:

- the first group is animals with a high genetic prediction of heifers by their paternal genetic potential;

- the second group is animals with good genetic potential of their fathers;

- the third group is animals with poor genetic potential.

On the basis of genomic assessment of the genetic potential of heifers by predicted indicators, it is determined whether or not bulls should be used for them. The selection of bulls took into account the parameters of the heifers (productivity, fat and protein content in milk, calving ease, height in the withers, limb indexes, udder, fertility). The results of genomic evaluation were compared with the actual indicators obtained from heifers after their first calving according to the data of external calving, live weight, the level of milk productivity, the level of labor and postnatal period, fertilization, live weight of calves. 
This scientific work is of an unfinished nature. In the future, all these indicators will be studied, taking into account lactation and the quality of the offspring.

\section{Results}

According to the results of the genomic evaluation it turned out that not all animals correspond to the expected results on the phenotypic features of their parents. The given analysis of 10 heifers with the forecast of their level of milk productivity, fat content in milk, protein has different values. If almost all heifers have positive prognosis in terms of fat and protein content, 7 animals have negative correlation in terms of milk (Table 1).

The predicted reliability for heifers ranges from 67.0 to $70.0 \%$. Further on, after insemination and calving of animals, the reliability of prediction of signs of milk productivity, milk quality and reproductive capacity will be determined.

Table 1. Indicators of genomic evaluation of heifers

\begin{tabular}{|c|c|c|c|c|c|c|c|c|c|c|}
\hline № & $\begin{array}{c}\text { No. } \\
\text { of the animal }\end{array}$ & DN & NM & Reability & $\begin{array}{l}\text { Milk, } \\
\text { pound }\end{array}$ & $\begin{array}{l}\text { Fat, } \\
\text { pound }\end{array}$ & $\begin{array}{l}\text { Protein, } \\
\text { pound }\end{array}$ & TPI & ISU & $\begin{array}{c}\text { LAIT, } \\
\mathrm{kg}\end{array}$ \\
\hline 1 & RU000263000518 & 02.02 .2015 & 165 & 69 & -317 & 4 & 17 & 1784 & 135 & -492 \\
\hline 2 & RU000263001756 & 12.05 .2016 & 220 & 70 & -376 & 15 & 5 & 1820 & 141 & -529 \\
\hline 3 & RU000263001611 & 24.02 .2016 & 314 & 68 & 600 & 40 & 21 & 2092 & 152 & 693 \\
\hline 4 & RU000263001742 & 14.04 .2016 & 218 & 69 & -30 & 12 & 4 & 1883 & 137 & 211 \\
\hline 5 & RU000263000948 & 27.11 .2015 & 48 & 67 & -11 & 12 & 4 & 1770 & 137 & 58 \\
\hline 6 & RU000263001759 & 18.05 .2016 & 45 & 67 & -371 & 16 & 1 & 1671 & 122 & -34 \\
\hline 7 & RU000263001598 & 30.01 .2016 & 174 & 67 & 509 & 7 & 20 & 1831 & 144 & 1033 \\
\hline 8 & RU000263001615 & 02.03 .2016 & 214 & 69 & 208 & 17 & 7 & 1848 & 133 & 117 \\
\hline 9 & RU000263001622 & 11.03 .2016 & 143 & 69 & -44 & 7 & 2 & 1836 & 130 & 151 \\
\hline 10 & RU000263001595 & 24.01 .2016 & 8 & 67 & -401 & 4 & -8 & 1612 & 97 & -343 \\
\hline
\end{tabular}

The analysis of heifers' productivity forecasts for their fathers has a positive tendency. Three animals are expected to increase their milk productivity from 200 to $600 \mathrm{~kg}$ (Table 2).

Table 2. Heifers' indicators by their fathers

\begin{tabular}{|l|c|c|c|c|}
\hline No. Of the heifer & $\begin{array}{c}\text { NM } \\
\text { of the } \\
\text { father }\end{array}$ & $\begin{array}{c}\text { NM of } \\
\text { heifers }\end{array}$ & $\begin{array}{c}\text { Milk, } \\
\text { pound } \\
\text { father }\end{array}$ & $\begin{array}{c}\text { Milk, pound of a } \\
\text { heifer in TPI }\end{array}$ \\
\hline RU000263001611 & 491 & 314 & 751 & 600 \\
\hline RU000263001598 & 291 & 174 & 852 & 509 \\
\hline RU000263001615 & 339 & 214 & 205 & 208 \\
\hline RU000263000948 & 171 & 48 & 676 & -11 \\
\hline RU000263001742 & 537 & 218 & 1342 & -30 \\
\hline RU000263001622 & 291 & 143 & 852 & -44 \\
\hline RU000263000945 & 129 & -12 & -76 & -50 \\
\hline RU000263000518 & 257 & 165 & 12 & -317 \\
\hline RU000263001759 & 491 & 45 & 751 & -371 \\
\hline RU000263001756 & 291 & 220 & 852 & -376 \\
\hline RU000263001595 & 291 & 8 & 852 & -401 \\
\hline RU000263000544 & 112 & -43 & 232 & -436 \\
\hline RU000263000503 & -25 & -190 & 351 & -516 \\
\hline
\end{tabular}

According to the results of the analysis of heifer RU000263001611 has a high value of productivity; the animal will have a high index of height in the withers. Such an animal can be used for the production of embryos.

The heifer RU000263001598 has an average protein, low fat value, so it is necessary to use it when inseminating a bull with high productivity, high fat index and good reproducibility. It can also be used to produce embryos.

The RU000263001615 heifer has average productivity, poor, low leg index values, so it should be used for insemination of the bull with good leg index values. It can be used to produce embryos.
The heifer RU000263001742 has average productivity values. Poor leg index value and high calving ease value. Therefore, a bull with a good limb index value and high productivity and low calving lightness should be used for this heifer. It can be used for embryo production.

All these heifers can be categorized as good. The RU000263000948 heifer has a lower than average productivity, so you need to use a bull with high productivity and easy calving.

The RU000263000518 heifer has a lower than average productivity, unbalanced body and udder values, so you need to use a bull with high productivity and good udder index of your daughters.

The RU000263001756 heifer has average fat and protein values, but very low milk values. Therefore, it is necessary to use a bull with a good leg index value and high productivity.

All these heifers can be classified as mediocre animals.

The heifer RU000263000544 is an animal with poor performance. We will use the best bulls, but only the third generation will have good genetic potential. Therefore, we recommend using it as a recipient of very good embryos or for meat products.

RU000263000540 Animal with a bad record. We will use the best bulls, but only the third generation will have good genetic potential. Therefore, we recommend using it as a recipient of very good embryos, or for meat products (data in the appendix).

Chick RU000263001590 Animal with poor performance. We will use the best bulls, but only the third generation will have good genetic potential. Therefore, we recommend using it as a recipient of very good embryos or for meat products (data in the annex). 
Chick RU000263000520 Animal with poor performance. We will use the best bulls, but only the third generation will have good genetic potential. Therefore, we recommend using it as a recipient of very good embryos, or for meat products (data in the annex).

All of these heifers can be classified as weak animals.

Based on the results of the genomic assessment, the animals classified as good have a high genetic potential for embryo production and will mainly determine the future of the herd. Animal categories - mediocre - for them it is necessary to select bulls with the qualities that allow them to improve their deficiencies to the maximum extent possible. Chicks in the category - weak animals - should not be left for reproduction, but rather inseminated by bulls-producers of meat breeds to obtain high-quality meat products.

Discussion. To obtain information about the animal's genome, a tissue sample is taken from which the DNA molecule is extracted. It is then placed on a chip that analyzes the sequence in which the nucleotides are arranged and the uniformity of their arrangement across the chromosomes. However, a number of researchers $[7,6,12]$ believe that the distribution of chromosomes in animals does not depend on the sample (blood, wool, tissue, or seed). In their opinion, SNP "Snip" markers and functionally important genes in animals and their ancestors remain in place for several generations, which makes it possible to look into the future of a young animal (heifer).

Despite the mysterious name, the genomic evaluation for breeding purposes is quite simple. Previously, breeders knew about the genetic potential of young animals from the averaged indices of their parents. These indicators represented the average value predicted the transmission capacity of the parents of the animal, which did not allow to determine which genes their descendants inherited - the best or worst average, which lengthened the period of determining the quality indicators to 5 years until their daughter's lactation.

At present, up to 95 respondents are interested in the possibility of determining the genetic status and potential in newborn heifers [6,7]. Introduction of genomic assessment of heifers at an early age allows the owners to quickly solve the following questions: which heifers to keep for reproduction of the herd; which heifers can be sold as breeding heifers; which heifers to fix for which bulls. As well as genomic evaluation can increase the volume and improve the quality of milk produced, and use its results when buying heifers and nonheifers. The results of our genomic assessment coincide with the opinions of a number of researchers in the United States and France $[2,6]$.

\section{Conclusion}

Genomic chick assessment analyses compare genomic and phenotypic data and provide an excellent indicator of the predictive feasibility of genomic examination of female specimens from which many benefits can be derived. It is an opportunity for dairy farmers and dairy farmers to identify the most outstanding cows and heifers who can become mothers of the next generation of bulls working in artificial insemination, and the dairy industry as a whole will benefit from the increased introduction of animal genome research into commercial herds. The more information the owners and specialists have about the repair young animals, the more they will be able to make the most effective decisions to increase profits. At present, these simple decisions determine which heifers to save and use for herd repair, which to sell and which to inseminate with seeds separated by sex. Genome evaluation promises more interesting perspectives for the development of an algorithm of animal sensitivity to a particular veterinary drug or to form diets for certain groups of animals whose nutritional needs have been predicted with the help of genomics. In order to realize this potential, some research and data are needed.

The researches carried out by us on genomic estimation of heifers in JSK "Niva" specify perspectivity of its use in selection-breeding work as the further accelerated increase in efficiency of dairy cattle breeding without use of progressive methods of an estimation of repair young animals will not allow to raise in short terms productive, breed and qualitative parameters of cows' dairy productivity. At present, out of 20 genomically evaluated heifers, 17 heads have confirmed the results of the conducted research.

\section{References}

1. T.I. Antonenko, N. Efimova, V. Zolotareva, Innovations and modern technologies in agricultural production and processing (Stavropol, 2016)

2. I.M. Donnik, S.V. Mymrin, Chief zootechnician, 8, 20-32 (2016)

3. C.V. Mymrin, V.S. Mymrin, I.M. Donnik, Agrar Bull. of the Urals, 4(222), 28-30 (2014)

4. E.L. Nicolazzi, S. Biffani, F. Biscarini, P. Orozco terWengel, A. Caprera, N. Nazzicari, A. Stella, Animal Genetics, 4(46), 343-353 (2015)

5. D.M. Nikulin, Niva Uralia, 7, 129 (2015)

6. Yu. Ruban, V.A. Danshin, A.M. Fedota, Animal Biol., 1(18), 117-125 (2016)

7. M. Bichard, W.G. de L. Luff, J.A. Woolliams, T.A. Cooper, S.A.E. Eaglen, G.R. Wiggans, J. Jenko, H.J. Huson, D.R. Morrice, J. of diary Sci., 99, 5508-5515 (2016)

8. G.A. Sharkaeva, Theory and Pract. of Modern Sci., 2(20), 675-679 (2017)

9. M. Milanesi, D. Vicario, A. Stella, A. Valentini, P. Ajmone-Marsan, S. Biffani, F. Biscarini, G. Jansen, E.L. Nicolazzi, Animal Genetics, 1, 69-72 (2015)

10. A.A. Belous, H. Amerkhanov, Student Science - the first step in academic science (Cheboksary, 2017) 
11. H.M. Kostomakhin, A. Khovankina, Chief zootechnic., 11, 16-25 (2016)

12. B.A. Grashin, A. Grashin, Bulletin of Samara State Agricult. Acad., 2, 89-93 (2016)

13. A.A. Sermyagin, E. Gladyr, S. Kharitonov, A. Ermilov, I. Yanchukov, N. Strekozov, N. Zinovyeva, Ways to extend the productive life of dairy cows by optimizing breeding, housing and feeding technologies (Dubrovitz, 2015)

14. L. Hansen, Animal Husbandry of Russia, 1, 40-41 (2014)
15. K.V. Plemyashov, V.V. Labinov, E.I. Saksa, M.G. Smaragdov, A.A. Kudinov, A.V. Petrova, Milk and Beef Cattle Breed., 1, 2-5 (2016)

16. C.F. Silvin, N.V. Sulyga, New Sci.: Theoret. and Pract. Views, 10-2, 226 (2016)

17. A.M. Winkelman, D.L. Johnson, B.L. Harris, J. Dairy Sci., 98(1), 659-75 (2015)

18. H.A. Popov, V.A. Ivanov, Z.K. Miyuts, Chief zootechnic., 9, 16-23 (2017) 